\title{
EFICAZ COOPERACIÓN DE LA IGLESIA DE ÁVILA EN LA INSTAURACIÓN RENOVADORA DEL OBISPADO DE MÁLAGA
}

\author{
POR \\ VIDAL GONZÁLEZ SÁNCHEZ \\ Director de los Archivos Eclesiásticos de Málaga
}

\section{RESUMEN}

Cuando en el afio 1487 la tierra de Málaga y su antiguo obispado retomaban al ámbito de la Cristiandad mediante el esfuerzo bélico que pusieron en marcha los Reyes Católicos, alentados por la Sede Apostólica que lo elevó a rango de Cruzada, la sede episcopal abulense se ballaba regida por el benemérito prelado Fray Hernando de Talavera. Aunque fray Hernando de Talavera no nunca fue obispo de Málaga, fue, sin embargo, un personaje benefactor de esta Iglesia. Él puso los cimientos de lo que luego llegó a ser un obispado insigne por la categoria de muchos de sus prelados. Por todo lo expuesto, no es ilogico proclamar que la Iglesia de Ávila jugó un papel importante en la acción misional de la instauración del obispado de Málaga.

\begin{abstract}
Agstract
In 1487 the land of Málaga and its ancient bishopric was tourning back to the area of the Christianity through the warlike effort put under wayby the Catholic Kings, encouraged by the Apostolic See that increased it to Crusade range, the Espiscopal of Ávila was found governed by the meritorious prelate Hernando de Talavera. Though Hernando of Talavera was not ever been bishop of Málaga, it was, however, a great prelate of this Church. He gives the basics in order that later its became an illustrious bishopric by the category of many of his prelates. For this reason, it is not illogical to proclaim that the Avila Church played a important role in the misional action of the setting-up of the Malaga bishopric.
\end{abstract}

Actas del I Congreso de Historia de la Iglesia y el Mundo Hispárico

Hispania Sacra, $\$ 2$ (2000) 
El momento preciso del retorno de la tierra y obispado de Málaga al ámbito de la Cristiandad en el mes de agosto del año 1487, mediante el esfuerzo eficaz de los monarcas castellanos Fernando e Isabel, coincide con una situación peculiar en la venerable Iglesia de Ávila. Se habían cumplido dos años desde que por bula del Papa Inocencio VIII dada en Roma a 26 de agosto de 1485, Fray Hernando de Talavera, monje jerónimo, Prior del Monasterio de Santa María de Prado a las afueras de Valladolid, había sido promovido tan importante obispado.

Pero este varón virtuoso que reunía en sí excepcionales cualidades, Confesor y Consejero Real, seguiría desempeñando estos cometidos junto con el gobierno de su flamante diócesis, porque era requerido de contínuo para orientar y dar solución a muchos de los negocios de Estado. Su característica intelectual de teólogo moralista, formado en la Universidad salmantina, hizo que permaneciera en todo momento avalando las funciones de director de conciencia de ambos monarcas, Pastor ejemplar de su grey, catequista por vocación y "hombre de Estado" del que en concreto la reina Isabel la Católica nunca quiso prescindir y al que consultó en todos los asuntos graves hasta el fin de sus días.

El Prior de Prado no pudo menos de aceptar ser el pastor del extenso obispado de Ávila, él que no «...quería ser obispo hasta no serlo de Granada» como decía con cierto gracejo y visos de excusa para no serlo nunca, juzgando que lo de Granada era cosa muy incierta ya que estaba en manos de los sarracenos y era bien defendida. Pero una vez consagrado como obispo de Ávila, su dedicación a la diócesis llegó a plantear un grave contratiempo para la reina ya que su consejero debía abandonar la Corte donde se le consideraba como imprescindible. Fray Hernando era de aquella clase de hombres que cumplían profundamente con su deber y pensaba que el Pastor de las almas debía estar siempre en medio de su rebaño. El mismo arguía a los reyes cuando le apremiaban a venir hasta la Corte, resaltando su nueva condición de prelado: «pues me echastes la carga a cuestas, dexádmela llevar...n' ${ }^{1}$. Se refería a la carga de la cura de almas en su nuevo obispado muy extenso, profundamente piadoso y necesitado de pastor residente. $Y$ es que la Reina en particular, que había conseguido y se había acostumbrado en los años jóvenes del inicio de su reinado a que Fray Hernando residiese de modo continuado a la Corte por lo que no podía sufrir la ausencia de tan prudente consejero por lo que el historiador de la Orden Jerónima nos dirá que: «tornava a darle prisa que viniese y mirase que las cosas se hacían mal con cartas; que tantos negocios y tan largos, mal se podían entender por correos» ${ }^{2}$. Vuestras cartas, dice la reina a su confesor: «Me dan la vida y

' B.N. Madrid. Ms.9495. Breve Suma. Fol.21.

2 J. SigǘñZ, Historia de la Orden de San Jerónimo. II, Cap. X, p. xxi. 
que no puedo dezir ni encarezer, como muchas vezes digo quánto me aprovechan (...). No es razón de cansar ni dexarlas, sino escrebir con quantos acá vinieren (...). Y querría yo que aún más las extendiésedes y más particularmente de cada cosa y de todas las cosas que hubieren de negocios y de las cosas que ay que acá pasan (...) y lo que toca a aquellas islas que alló Colón y sobre ellas mesmas que dezis que nunca os escrebí (...) y de los casamientos de nuestros hijos (...). Y no sólo en estos negocios, que son los mayores, mas en todos los de nuestros reynos y de la buena governación dellos querría que particularmente me escribiésedes en todo, vuestro parezer (...). No hay pasatiempo en que más yo huelgue (...). Esto os ruego yo mucho, que no os escuseys de escribir vuestro parecer en todo en tanto nos veemos, ni os escuseys en que no estays en las cosas y que estays ausente, porque bien se yo que, ausente, será mejor el consejo, que de otro, presente» ${ }^{3}$. Por esta evidente necesidad de su presencia en la Corte en todo tiempo, el obispo de Ávila hubo de alejarse muchas veces de su obispado para preparar las diversas etapas de las campañas de la guerra de Granada como la de Vélez y Málaga. Procedente de Córdoba donde se hallaba instalado el cuartel general llegó al Real sobre la ciudad de Málaga, a mediados del mes de mayo, el día 16, del afio 1487. Venía formando parte de la comitiva de la reina, junto con el Cardenal de Espafia, don Pedro González de Mendoza y sus mesnadas. Es tradición muy afianzada que, aunque se le asignó una tienda en el campamento, de las de « 20 cuerdas» como las demás de los nobles allí castramentados, él la reservó para su oratorio y oficina de trabajo mientras que se retiraba a descansar a una humilde choza hecha de ramajes como un anacoreta. Alli se ocupó Fray Hernando durante los casi cuatro meses que permaneció en el Real hasta la toma de la ciudad, de todo lo concerniente al diseño, planificación y ordenamiento del obispado de Málaga con su iglesia catedral, que sería la mezquita mayor musulmana, las cuatro parroquias iniciales, hospitales, monasterios de varones, algunos de los cuales ya tenían sus representantes en el campamento como franciscanos, dominicos, mínimos etc. Más otros como mercedarios y trinitarios que incluso aquí ya se ocupaban en tareas de rescate de cautivos que estaban en manos de sarracenos en el reino moro de Granada o allende del mar.

Para poder efectuar la proyectada restauración -que no creación del obispado malacitano, los monarcas habían recibido bulas papales con facultades expresas y comisión al Cardenal Mendoza quien debería operar como Juez Ejecutor de las mismas y proceder conforme a Derecho, a la erección de la Iglesia y antiquísimo obispado de Málaga por lo que el obispo de Ávila, por delegación real, fue el motor y el realizador de toda esta feliz restauración.

${ }^{3}$ Biblioteca del Real Monasterio de El Escorial, L. I, 13, Fols. 13-18. 
Oigamos al que luego sería obispo de la ciudad recuperada don Pedro Díaz de Toledo quien como testigo de excepción del hecho jurídico de esta restauración sobre los cimientos de lo que fuera su Sede paleo-cristiana, que fue pujante hasta el final de la época visigótica. Se devolvía ahora a esta Iglesia a la vida y al recuerdo de prelados tan preclaros como Patricio, Severo o Julián, cruelmente atormentado por los sarracenos al tiempo de la invasión del solar ibérico. La restauración e «Institución» de la Sede Malacitana se efectuaba mediante la protección de la Corona y la autoridad de legada en el Reverendísimo don Pedro González de Mendoza y Santillana, Gran Cardenal de España, Patriarca Alejandrino, Arzobispo de Toledo, Primado de las Españas, Canciller de los Reinos de Castilla y de León etc., en virtud de las bulas apostólicas a él cometidas, por la autoridad del Papa Inocencio VIII.

Éstas fueron dos: La primera fechada en Roma junto a San Pedro el 4 de agosto de 1486 cuyo título inicial es: «Ad illam fidei constantiam». Por ella se facultaba para la creación de iglesias catedrales, colegiales, parroquiales, beneficios para el personal que las sirviese etc. Por la segunda, de idéntico título, expedida en Roma y también dirigida a los Reyes Católicos, fechada en 23 de agosto del mismo affo, se facultaba para crear monasterios de ambos sexos tanto en los lugares reconquistados del Reino moro de Granada, como en las Islas Canarias y en otros territorios, monasterios que se creaban con el fin exclusivo de que con su predicación y con el ejemplo de los religiosos, los nuevos cristianos sean instruidos en la fe de Cristo 4 .

Don Pedro de Toledo siendo ya obispo residente de Málaga, describe cómo estando en Zaragoza con toda la Corte a la que acompañaba como Limosnero Mayor de la Reina, el acto solemne de la publicación de la Carta Ejecutoria de la «Institución» de la Iglesia de Málaga:

«(...) el ylustre e Reverendissimo Sefior don Pero Gonçáles de Mendoça (...) fizo e instituyó por bula apostólica a él cometida e dirigida por nuestro muy santo padre Ynoçençio otavo e por mandamiento de los cristianísimos, muy altos e muy poderosos prínçipes Rey e Reyna nuestros seffores e en su nonbre, al dicho Señor Cardenal, presentada por el muy Reverendo yn Christo padre e seffor, don Fernando de Talavera, obispo de Avila, confesor y del Consejo de Sus Altezas, la qual ereç̧ión e instituçión el dicho Reverendíssimo señor Cardenal fizo en presençia de Sus Altezas e del dicho señor Obispo de Avila e nuestra e de los del su muy alto Consejo en la dicha çibdad de Çaragoça que es en el Reyno de Aragón, a treze días del mes de febrero, afoo del nasçimiento de nuestro Seffor Jhesu Christo de mill e quatroçientos e ochenta e ocho afios (...).

La qual sobredicha institución e ordenaçión de nuestra Yglesia fecha por el Reverendíssimo Seffor Cardenal, nos el sobredicho don Pedro de Toledo, obispo de Málaga, reçe-

\footnotetext{
${ }^{4}$ AGS: Patronato Real, Legajo 68, Fols. 3, 4 y 20.
} 
bimos e admitimos por nos e por nuestra Yglesia ante Sus Altezas e los del su Consejo en el dicho día (...) $m^{5}$.

Todo este proceso había tenido su comienzo en el Real sobre Málaga pues según noticia que nos suministra el Libro del Limosnero, el obispo de Ávila, siguiendo instrucciones de los monarcas, sacaba por sí y con la colaboración de su secretario particular, un traslado de la primera de las bulas sobre «el patronazgo de las iglesias" ganadas de nuevo a los moros. Este traslado autorizado y escrito con sumo cuidado bajo la responsabilidad directa del Fray Hernando de Talavera, debió ser un verdadero documento magistral ya que se pagó por dicho traslado incluido el pergamino, la notable cantidad de un florín de oro $^{6}$. Este fue el documento que el obispo de Ávila, según nos refiere don Pedro de Toledo, entregó con la mayor solemnidad a los Reyes en presencia de toda la Corte, y de muchos capitanes y soldados de su ejército presentes en el Real. La ceremonia debió tener lugar el día 18 de junio festividad de los santos Ciriaco y Paula después de celebrada una misa solemne en el alfaneque del que se habla junto a la tienda de la reina. Por su dedicación al estudio de la historia y de las antigüedades malagueñas, Fray Hernando reivindicó el patronazgo de estos santos mártires para la ciudad de Málaga ya que según una tradición venerable, derramaron su sangre confesando a Cristo, aunque la crítica más reciente lo ponga en duda. Una de las cuatro parroquias iniciales de la ciudad, llevaría el título de Los Santos Mártires San Ciriaco y Santa Paula y por intervención de Talavera, el escudo que los Reyes Católicos concedieron a Málaga ostentaría las efigies de Los Mártires en la torre más alta del castillo de Gibralfaro?

El mismo Papa Inocencio VIII al contestar a la misiva que los monarcas españoles le enviaron comunicándole la toma de la ciudad, hace referencia a la «memoria de los santos mártires Ciriaco y Paula, quienes por la misma fe cristiana, dieron en la antigüedad sus vidas en aquella ciudad de Málaga».

Como nuestro propósito en este estudio es poner de manifiesto la vinculación y la ayuda de la Iglesia de Ávila con el renaciente obispado malacitano a III.

' ACC Málaga: Códice de los Estatutos de don Pedro de Toledo, Leg. 674, Folios II y

${ }^{6}$ El libro del limosnero de Isabel la Católica, transcripción y edición por Eloy Benito Ruano, Ministerio de Asuntos Sociales, Madrid, 1989, Fol. 36 v.

7 AGS: Leg. Segovia, 30 de agosto de 1494. «Don Fernando e doha Ysabel por la gracia de Dios Rey e Reyna de Castilla e de León etc. (...) acatando de cómo la dicha çibdad de Málaga por la graçia de Dios fue ganada por conquista e los moros de allí fueron presos e captivos, le damos por armas la forma de la çibdad y castillo de Gibralfaro con el corral de los captivos en un campo colorado, e para la reverencia de los Santos Bienaventurados Mártires San Ciriaco y Santa Paula que en ella fueron martirizados, poner su Ymagen de cada uno dellos en par de la torre de Gibralfaro.". 
través del obispo de aquélla, hemos de volver a los días del campamento cristiano, plantado al pie de los muros de la ciudad ocupada y defendida bravamente por los menfíes. Perseveró durante toda la Cruzada al lado del ejército y su colaboración en la victoria sobre Málaga fue muy importante. Verdad es que sus muchos servicios le serían luego de algún modo recompensados mediante los repartimientos por merced que recibió de sus Altezas. Le fueron repartidas en lugares muy próximos a Málaga, huertas, tierras de labrantío y otras heredades además de casas en el núcleo de la ciudad y del mismo modo a sus familiares y criados como más tarde veremos. Porque el obispo de Ávila no se contentó con la contribución de su esfuerzo personal sino que se participó en la campaña con todo un equipo de colaboradores, familiares y criados y a cada uno de ellos les encomendó tareas importantes.

Pedro Mártir de Anglería diría de él en carta dirigida al Conde de Tendilla que «(...) por él se recuperó del poder de los moros el Reyno de Granada». El historiador eclesiástico de Granada Bermúdez Pedraza en frase audaz, afirma de Fray Hernando de Talavera: «hizo más guerra a los moros este soldado de Cristo con sus consejos, oraciones y disciplinas que todos los españoles juntos, con las armas» ${ }^{8}$.

Con su equilibrado consejo, atemperó más de una vez los ímpetus del Rey don Fernando cuando propendía al rigor con los enemigos que se mostraban muy altivos. Talavera suplicó de muchos modos clemencia al monarca, aunque no pudiera a veces, más que alcanzar una atenuación en el castigo. Conquistada Málaga, Abraham El Zenet un moro ilustre que en cierta escaramuza que llevó a cabo durante los combates por los alrededores del campamento cristiano, rehusó alancear a ciertos muchachos cristianos que jugaban en torno al Real, porque no habia visto aún barba en ellos, alcanzó perdón mediante la intercesión del obispo de Ávila y aún consiguió para él dádivas y mercedes.

Tenía formado como un «estado mayor de la fe» en el que había integrado a los numerosos frailes y clérigos que andaban por diversos motivos en el Real, alguno de los cuales recibio heridas de los moros, de los cuales se valía como colaboradores para el apostolado entre la numerosa tropa. Predicaciones, charlas, actos de piedad, atención espiritual y sacramental, corrección de desmanes, apostolado del bien hablar, desterrando la blasfemia y la maledicencia eran tareas llevadas a cabo bajo la dirección de aquel verdadero apóstol.

Dado que esta empresa guerrera atañía a la difusión de la fe cristiana que era "cosa divina» urgida por los Sumos Pontífices y muy arraigada en el sentir del pueblo espafiol, habia que encauzarla por caminos adecuados de vida cristiana.

${ }^{8}$ F. Bermúdez Pedraza, Historia Eclesiástica, Principios y progresos de la ciudad y religión católica de Granada, por don..., Granada, 1638.

Actas del I Congreso de Historia de la Iglesia y el Mundo Hispánico

Hispania Sacra, $52(2000)$ 
Ante todo había que obtener del Altísimo la ayuda necesaria, importunándole en todo tiempo con la oración pública y privada. Después de las campañas de 1482 y de 1485 con muy buenos resultados, los Reyes desde Córdoba una vez despedidas sus tropas, acordaron escribir al Papa dándole cuenta de las victorias que Dios les había concedido contra los moros, enemigos de nuestra fe... «otrosí le enbiaron decir como, mediante el ayuda de Dios e de la Virgen gloriosa su madre, ellos entendían continuar su conquista fasta ganar todo aquel reyno (...). El Papa y los Cardenales, oyda aquella nueva, ovieron grand plazer; e el Papa, considerados los muchos gastos que en aquella conquista se requerían facer, otorgó segunda Cruzada con grandes yndulgencias....».

De ahí también el que los ejércitos cristianos recibiesen la adecuada atención espiritual como en el caso que nos ocupa. Un prelado español predicaba a todo el Colegio Cardenalicio de Roma en medio de una fiesta que se celebró en los últimos días de octubre del año 1487 para dar gracias a Dios por la conquista de Málaga y en su discurso abundó en estas ideas:

«No van tras este ejército ni rameras ni prostitutas, nada de alcahuetería ni de embustes, ni se permiten en absoluto los juegos de azar, por la sencilla razón de que así nadie podtá tener ocasión de reclamaciones ni venganzas. Pero es que además, en los anios organizativos del ejército, la propia Serenísima Reina de Castilla fijó su residencia en la ciudad de Córdoba muy cristiana y muy cercana al teatro de la guerra, para poder atender mejor al ejército y proporcionarle toda la asistencia necesaria inchuida la espiritual, con la mayor presteza. Ponla la Soberana especial cuidado en preparar sagrados omamentos bordándolos con seda y oro y vasos sagrados también de oro y plata y los demás utensilios necesarios para un culto digno en los templos erigidos en las villas y ciudades reconquistadas. Casi a diario recorre con sus pies descalzos, en procesión de súplica, las iglesias de aquella ciudad, soportando con alegria la dureza del suelo, despreciando la blandenguería que ella juzgaba propia de mujerzuelas sin valor. Lo hacía todo con una incretble fortaleza de la que por don especial, fue dotada por el Autor de la naturaleza, en lo que era superior a las demás mujeres de su tiempon ${ }^{10}$.

El mismo documento relata cómo en la capilla del palacio cordobés un centenar de sus damas, por turnos, hacian vela ininterrumpidamente, para impetrar de Dios el feliz resultado de la empresa guerrera...

«(...) en cuyo número de cien está incluida la propia reina atenta a su turno de vela, la cual avisada de la hora en que le corresponde hacer su oración, todo lo deja para cumplir escrupulosamente su compromisos ${ }^{11}$.

${ }^{9}$ F. Pulgar, Crónica de los Reyes Católicos, Edic. J. Mata Carriazo, Madrid, 1943, II Espasa Calpe, Cap. CLXXI, pp. 188-189.

${ }^{10}$ V. GONZÁlez SÁnChez, MALAGA: Perfiles de su Historia en documentos del Archivo Catedral (1487-1516), Málaga, 1994, pp. 42-47.

11 Ibid., L. c. 
En este mismo documento se narran los éxitos guerreros del Rey con su ejército sabiamente organizado hasta en los mínimos detalles, de modo que superaba en eficacia a todas las formaciones militares de mucho tiempo atrás. En él se daba culto a Dios con un considerable número de misas y sacrificios y otros oficios con tegularmente se celebraban; además, los sermones, alocuciones, confesiones, piadosas y constantes exhortaciones al cumplimiento de la Ley de Dios, lo que hacian cada día celosos sacerdotes, escogidos entre los mejores, letrados y cumplidores de sus deberes. Todo iba encaminado a dar rubustez y fortaleza al espíritu de los soldados, de donde se colige que estos Católicos Príncipes, tenían grabado a fuego en su alma el deseo de propagar la fe cristiana y no simplemente conquistar nuevas tierras para incremento de sus reinos" 12 .

Con estas premisas que juzgamos necesarias, podemos entender mejor el sentido de una real cédula que, firmada de su mano, enviaba la reina Isabel al Cabildo catedral, clero y fieles del obispado de Málaga. Consciente del valor de la oración "al Dios de los ejércitos», recordando el relato del libro del Exodo en la victoria de Israel contra los amalecitas, dice la reina que las oraciones y misas y otros sufragios, pueden servir de gran provecho. La soberana ruega y encarga en dicha carta, que en la iglesia catedral y en los demás templos del obispado, se hagan procesiones de penitencia con súplicas y sufragios como se hace en ocasiones de gran necesidad, para que Dios quiera dar por fin, una victoria amplia a los Reyes y al pueblo con la conquista de la ciudad de Granada, último eslabón para engarzarlo en el ámbito de la Cristiandad.

La Reina cierra su misiva afirmando que si el clero y fieles acceden a su ruego: «(...) demás del serviçio que hareis a Nuestro Sef́or, CUYA ES LA CAUSA, a my hareis agradable plasen ${ }^{13}$.

El Papa Inocencio VIII, escribía a la Reina Isabel sobre la guerra de Granada: «Queridísima hija en Cristo: Bien se aprecia cuán grande se tu empeño por arrancar de cuajo y borrar del solar hispano la perfidia mahometana, empresa muy meritoria, acepta a Dios y reportadora de alabanza para Vuestra Majestad. A ella te animamos.”

A ambos monarcas les exhorta:

"Se me ocurre animaros a que sigáis sin desfallecer la guerra que tenéis comenzada contra los sarracenos. Y puesto que lo hacéis con toda justicia para gloria de Dios, no

12 Ibid., L. c.

13 ACCM-Leg. 13. Pieza 6. Sevilla 7 de abril, 1491. El subrayado y resaltado es nuestro para hacer ver la razón poderosa que se aduce y que es la misma que mueve a la guerra. Es frase repetida muchas veces y siempre en confirmación de lo sublime de la empresa guerrera. Así cuando en la toma de Loja la soberana visitó a los enfermos y heridos en la lucha, les animaba en medio de sus dolores y les prometía por su parte, remuneración en esta vida pero que: "Dios, cuya era la causa, no se olvidaría de lo remunerar en la otra." (Pulgar, Crónica..., II, cap. CLXXXIX).

Actas del I Congreso de Historia de la Iglesia y el Mundo Hispánico

Hispania Sacra, 52 (2000) 
puede suceder sino que la concluyáis con éxito elcual os daré el mismo Dios, de cuya causa se trata» («de cujus causa agiturn).

Si con el paso del tiempo y la evolución del pensamiento el concepto de «Cruzada» no se valora en su original criterio, la culpa no será de la altura singular de tal empresa, sino del menosprecio que hoy se tiene para con unos valores que entonces gozaron de vigencia indiscutible y que Fray Hernando de Talavera inculcó repetidamente en el ánimo de los cruzados.

\section{EL PRIMER OBISPO DE MÁLAGA}

Con la irrupción de los sarracenos en el año 711, la floreciente cristiandad del obispado de Málaga, al cabo de poco tiempo sucumbió y de modo total fue erradicada con la llegada de los almohades. Sin embargo nunca se interrumpió la serie y sucesión de los obispos de Málaga aunque tuviesen que vivir y sufrir un largo exilio de su Sede Episcopal. Tenemos algunas noticias de los últimos obispos titulares «in partibus infidelium», que no residenciales, puesto que en toda la tierra de Málaga no se encontró ni un solo cristiano mozárabe al tiempo de la reconquista.

Don Pedro Díaz de Toledo y Ovalle, presente durante todo el tiempo que duró el cerco a la ciudad de Málaga y colaborador en todas las tareas apostólicas con el obispo de Ávila, tomó el relevo del gobierno ya in situ de la grey malacitana, formada en los primeros tiempos por soldados del ejército de los Reyes Católicos y por inmigrantes cristianos que vinieron de otras regiones espaffolas.

Pedro Díaz de Toledo nació en Alcalá de Henares y a partir de datos congruentes, podemos afirmar que hacia el año 1425. Su padre fue don Hernando Díaz de Toledo y su madre, doña Juana de Ovalle. En la capilla de Santa María de la iglesia colegial de Alcalá tenían sus sepulcros su abuela paterna, su hermana María y su padre, el Doctor Hernán Díaz de Toledo quien había sido hombre de letras, experto en Leyes, «Relator y Oydor Real y secretario de la Corte de Juan II de Castilla y luego también de su hijo Enrique IV».

Por la ascendencia de su apellido materno, procedia de las localidades gallegas de Redondela y La Salceda del concejo de Túy. Andando los tiempos vendrían nuevos nombres que darían más lustre a los Ovalle como el fundador de Guatemala o como el mercedario fray Nicolás de Ovalle, esclarecido vecino de Lima en el Virreinato del Perú, o don Juan de Ovalle y Villena, del Consejo de Felipe II. Los Ovalle tenían por armas escudo acuartelado con el primero y cuarto de oro, con tres palos de azur y el segundo y tercero de gules, 
con tres espadas de oro puestos al palo. En el archivo catedralicio de Málaga tuve la suerte de identificar un Sacramentario, códice gótico que junto con otros dos cantorales, presentan espléndidos escudos de armas del obispo Doctor Toledo.

Pertenecía este obispo a aquella clase de personas de origen social medio, nada opulento pero con una formación doctrinal muy cultivada, gentes sin soberbia de alcurnia a quienes los Reyes Católicos asociaron a las arduas tareas de gobierno lo cual fructificó en óptimos resultados, como afirmara Hurtado de Mendoza en su obra sobre la guerra de Granada. Es cierto que don Pedro de Toledo se formó científicamente antes del establecimiento de este plan educativo, pero él recibió también la benéfica influencia de los Colegios Mayores Universitarios. De su época de estudiante en Salamanca, nació la estrecha amistad entre un puñado de colegiales de los que contamos a: El Cardenal don Pedro González - de Mendoza, Hernando de Talavera, Pedro Díaz de Toledo, Francisco Jiménez de Cisneros, Diego de Haro y Villaescusa quien fue también obispo de Málaga, Elio Antonio de Nebrija, Alonso de Madrigal quien más tarde recibiría el sobrenombre de «El Tostado», etc., cuyas vidas se iban a cruzar y entrelazar andando los tiempos para dar frutos de provecho para la Iglesia. Toledo fue «familiar y comensal» en el obispado abulense siendo obispo Talavera y Vicario General del Arzobispado de Toledo con el citado Cardenal. Villaescusa sería Arcediano de Olmedo, Provisor de Ávila con Talavera como obispo, Deán de Jaén y luego primer Deán de Granada. Con Nebrija de quien había sido discípulo, se opuso Villaescusa a la cátedra de Retórica en Salamanca y la ganó. Y para no alargar más esta digresión, terminemos diciendo que a don Diego Ramirez de Villaescusa le cupo el honor de entender en la publicación de las "Obras del Tostado», parte de las cuales había ya publicado Cisneros como complemento a su Biblia políglota ${ }^{14}$.

Lo más significativo de todo esto es que todos estos hombres ilustres, fueron discípulos en la escuela de virtud que para clérigos jóvenes fundó el virtuosisimo Fray Hernando de Talavera tanto en su obispado de Ávila como en su casa, ya de Arzobispo de Granada. Don Pedro de Toledo en aquella kescuela de santos» se aficionó a la virtud admirable del maestro, en toda su vida le veneró, le pidió consejo y ayuda y le solia llamar como lo hace en su testamento, su «sefior e padre» ${ }^{15}$. Por este afecto reverencial a la persona y a la Orden que representaba, pretendió don Pedro fundar monasterio de Jerónimos en Málaga pero hubo

${ }^{14}$ F. Garcia Olmedo, Diego Ramirez de Villaescusa (1459-1537) fundador del Colegio de Cuenca y autor de los Cuatro diálogos sobre la muerte del Principe don Juan por..., Editora Nacional, Madrid, 1944, pp. 156-159.

is A.h.P.m., Leg. 17, Fol. 620, Testamento del obispo Toledo.

Actas del I Congreso de Historia de la Iglesia y el Mundo Hispánico

Hispania Sacra, 52 (2000) 
de ceder tal y tan justo honor a la ciudad de Granada. A cambio, fundó en la catedral-mezquita de la ciudad malacitana, una capilla en honor del Doctor San Jerónimo en la que quiso enterrarse. No logró verla edificada en sus días pero su albacea y testamentario el Arzobispo Talavera se cuidó de terminar su construcción y la dotó espléndidamente conforme a la voluntad del fundador, por documento dado en Granada en diciembre de $1507^{16}$.

Don Pedro de Toledo, después de haber sido canónigo de Sevilla durante 30 años, capellán de la casa del Marqués de Santillana don Iŕigo González de Mendoza y amigo entrafiable y colaborador con esta figura insigne de las letras castellanas, fue nombrado Limosnero Mayor de la Reina Católica ${ }^{17}$ y poco más tarde, obispo de Málaga. Los ojos de su "padre y maestro» se habían fijado en las cualidades de este hombre «varón de vida exemplar y docto en letras sagradas ${ }^{18}$ y junto con el Cardenal de Espafia le propusieron para que fuera presentado a Su Santidad por los Reyes para esta sede que habla de ser modélica en todo por ser la primera del Patronato de Granada. Desarrolló una actividad organizativa en un obispado dificil por quedar en tierra fronteriza de moros y junto con Talavera, se preocupó por preparar clero de buenas costumbres y bien instruido, reclutado de diversas diócesis españolas y especialmente de la abulense.

Como hombre de letras y humanista cabal, tradujo para el Marqués de Santillana obras clásicas de la antigüedad latina y griega y glosó, a requerimiento del monarca don Juan II los Proverbios que el Marqués de Santillana compusiera para la educación del Príncipe Heredero don Enrique.

La muerte del obispo Toledo acaeció en Granada adonde había viajado para saludar a los monarcas que se hallaban en ella. Allf redactó su testamento y entregó su alma a Dios, confortado con la presencia de su venerado «maestro» Fray Hernando, entre las últimas horas del día 21 y las primeras del 23 de agosto de 1499. Sus restos fueron trasladados a su sede episcopal donde recibieron sepultura provisional hasta que en 1507 quedó concluida su capilla-panteón llamada de «San Jerónimo».

Queda constancia de que en la fundación del monasterio de monjas de Santa Clara de Málaga, alentado y urgido repetidas veces por la Reina Católica, tuvo parte muy activa el obispo difunto aunque tampoco lograra verlo concluido en su vida. Fue otra de las herencias que dejó para su albacea el Arzobispo de Granada quien coronó esta obra. Entre las primeras monjas profesas de dicho

\footnotetext{
16 ACCM: Leg. 18, Pieza 13, Granada, 23 de enero, 1507.

17 AGS C. y S. Reales: Leg. 124, fols. 516 y 517 , aftos 1484 y 1486 . Reales cédulas nombrándole Capellán Real y Limosnero Mayor respectivamente.

18 Puloar, Crónica..., II, Edic. Mata Carriazo, Madrid, 1943, p. 335.
} 
monasterio se cuentan algunas de las Damas de la Reina Isabel como doña Juana y dofia Antonia de Valencia, doña Francisca Manrique de Lara, etc. ${ }^{19}$.

\section{El obispo de Ávila y el Limosnero Mayor de la Reina}

La fuerte relación de amistad de los años mozos se mantuvo siempre entre Toledo y Talavera aunque con una subordinación reverencial de aquel para con éste.

Andando los años, el destino acercaría aún más sus vidas de modo que la cooperación en sus tareas apostólicas llegó a complementarse. Ya hemos visto cómo el delicado cargo de Confesor de los monarcas que desempeñaba fray Hernando, le daba ocasión de descubrir el ámbito de la conciencia de los soberanos y más en concreto de la reina Isabel, mujer experimentada en la oración y meditación contemplativa, de gran recogimiento interior plenamente desarrollado. Esta vida interior se manifestaba mediante la práctica efectiva del amor al prójimo traduciéndose en actos de caridad y ayuda a los menesterosos tanto en el orden espiritual como en el puramente material. La constancia documental de las limosnas secretas a iglesias y monasterios, a pobres, heridos, enfermos, cautivos, desgraciados etc., es abrumadora. El Confesor y director de su conciencia era en muchas ocasiones el cauce de su caridad aunque un simple mozo de espuelas, un vasco llamado «Machín» o la famosa «beata Vitoria» fueron innumerables veces los agentes de sus limosnas siempre secretas...

Pero había otro cauce que podríamos calificar de «normal», que era el que desempeñaba el Limosnero Mayor.

Era cosa harto conocida que todos los reyes de Castilla tuvieran su limosnero, generalmente un clérigo que en su nombre, repartía limosnas a los menesterosos. La reina Isabel en esto se ajustaba a la costumbre pero con una diferencia esencial en el modo de ejercerla pues su innato celo por la Justicia hacía que donde no llegaba ésta, llegase la ayuda cristiana del mejor modo.

Los apuntes que el Limosnero don Pedro de Toledo llevaba en sus cuadernos para consignar cantidades que había recibido para limosnas, en orden a una posible justificación, debían ser destruidos periódicamente así como el Confesor debía convertir en ceniza las cartas de conciencia:

19 Para todo lo referente a la biografia de don Pedro de Toledo y para lo tocante a la fundación de este monasterio de Santa Clara de Málaga, ver nuestras obras: V. GoNZÁEZ SANCHEZ, En torno a un Centenario: ARTIFICES DE LA INSTITUCIÓN DE LA IGLESIA DE MALAGA 1487-1987 (en prensa) y MALAGA: Perfiles de su historia..., Málaga, 1994, pp. 180-227.

Actas del I Congreso de Historia de la Iglesia y el Mundo Hispánico Hispania Sacra, 52 (2000) 


\begin{abstract}
«Ruegoos (dice la reina a Fray Hernando), questa mi carta y todas las otras que os he escrito o las quemeys o las tengays en un cofre debaxo de vuestra llave, que persona nunca las vea $(.).)^{20}$.
\end{abstract}

Por suerte para nosotros, por razones desconocidas se salvaron tres de las cartas de conciencia y uno de los libros de limosnas. El limosnero Toledo recibia periódicamente cantidades de dinero de la soberana para hacer limosnas pero muy pocas pudo él hacer segín su propio criterio pues la propia reina, increíblemente atenta a las necesidades de los pobres, le tenía continuamente metiendo la mano en la barjoleta de modo que en la mayor parte de las limosnas, el limosnero añade esta coletilla: «Di lo por mandado de Su Alteza (...)».

De este modo el 14 de mayo de 1487, el obispo de Ávila y el Limosnero caminaban en el séquito de la soberana hacia el Real de Málaga cuando a la altura de La Rambla, aún en tierras de Córdoba se encontraron con un gallego que herido en Málaga regresaba a su tierra para curarse, el limosnero consigna que le dio «quinze reales para el camino fasta Mondoñedo. Mandolo el sr. Obispo de Ávila»»'

Por otro apunte vemos que: «Los maravedíes que yo Pedro de Toledo, Limosnero de la Reyna nuestra señora dí e pagué de los maravedíes de las penas de la Cámara por mandamiento de Su Alteza e por libramiento del obispo de Ávila son los siguientes...»

Entre los diversos pagos que hizo el limosnero real se cuenta una gran limosna de 140 fanegas de trigo a las monjas del monasterio de Sta. Marta de la Dueñas y otras 60 al monasterio de Santa María de Córdoba; otras cantidades para pagar el transporte de un retablo que desde talleres sevillanos, se llevaron a Málaga para su futura catedral.

Por indicación del obispo de Ávila, pagaba Toledo cierta cantidad a unos pintores que trasladaron al lienzo una vista panorámica del Real sobre Málaga o el importe de diez incensarios de plata para las iglesias de Málaga, los cuales se depositaron «en casa del obispo de Ávila». Hay limosnas a cautivos que se rescataron en Vélez, a heridos y enfermos etc.

Como la lista de estos relatos sería larga, terminaremos con este detalle que rezuma delicadeza cristiana: «Otrosí mandó la Reyna que diese de merendar a los cativos quando saliesen del alcaçava de Málaga, a la venida a la tienda de Sus Altezas, para lo qual se conpró que fueron para cativos de pan e de durasnos, peras e uvas y quasos, dos mil e quinientos maravedís, porquel vino se bol-

${ }^{20}$ Para todo este asunto, cfr. V. Rodríguez VALENCIA, Isabel la Católica en la opinión de españoles y extranjeros. I, Valladolid, 1970, pp. 342-372.

21 Libro del limosnero..., f. $35 \mathrm{v}$. 
vió a los que lo vendieron e todo lo otro mandó la Reyna nuestra señora que se diese al veedor y así se hizo $(. .).)^{22}$.

Hay una intervención singular de estos dos colaboradores de Su Alteza, en un asunto de mucha trascendencia como lo demostró el curso de la Historia aunque en este caso, la decisión iba por otros derroteros.

Un día caluroso del verano malagueño de 1487, apareció Cristóbal Colón en el Real sobre Málaga. No era este extranjero como otros que habían venido a participar en la lucha para lucrar indulgencias de Cruzada. Había llegado, llamado por los monarcas, para conocer la decisión sobre su proyecto descubridor, proyecto y pormenores que la Junta había estudiado y más que ningún otro, el obispo de Ávila a quien se había encomendado el estudio de su viabilidad. En la segunda quincena de mayo la reina había venido al Real para resolver y tratar «arduos problemas» que estaban pendientes y uno de ellos era el de Colón. La solución volvió a ser negativa aunque sin cerrar definitivamente las puertas de la esperanza. En la decisión de los reyes y en sus deliberaciones pesó como ninguna otra la del obispo de Ávila, Presidente de la Junta de sabios que estudiaron la cuestión. Ante todo aquel formidable aparato de guerra que poco a poco se iba desmontando, porque Málaga ya estaba conquistada, Colón rocibió la noticia abatido y contrariado. Sin embargo, él podía entender la razón de tal negativa porque lo primero era la guerra de Granada. También él como los soldados alborozados que partían para sus casas, iba a desandar aquellos caminos, agotados todos sus recursos dialécticos, machacado su orgullo y con una negativa punzante clavada en su alma. Él se retiraba, a diferencia de los otros, con su «guerro perdida»...

Pero aunque los reyes no le habían prestado ayuda para descubrir, sí la habian otorgado $-y$ generosa-, para que el «descubridon» pudiera subsistir. Por una nómina de Tesorería en 5 de mayo de 1487 aún en Córdoba, se daban a Cristóbal Colón «extranjero», 3.000 maravedís y se aducía esta razón: «Que está aquí faciendo algunas cosas conplideras al serviçio de Sus Altezas.» La nómina iba librada por Quintanilla pero por mandado del Obispo de Ávila. Por una segunda nómina de 3 de julio del mismo año, ya en plena campaña de Málaga le fueron librados otros 3.000 maravedís como «ayuda de costa», dádiva generosa para su mantenimiento ya que en esta ocasión no realizaba trabajo alguno para Sus Altezas, pero valía la protección que le otorgaba su benefactor Talavera. Por una tercera nómina de 27 de agosto en Málaga, se le conceden a Colón 4.000 maravedís para los gastos de su venida al Real sobre esta ciudad. La cédula de libramiento para este pago va extendida y firnada por el obispo de Ávila. Pocas fechas más adelante, el Limosnero consigna en su libro de limosnas este otro asiento: «Dí más a (...) portogués, 30 doblas castellanas que Su Alteza le mandó

23 Ibid. F.38r.

Actas del I Congreso de Historia de la Iglesia y el Mundo Hispánico Hispania Sacra, 52 (2000) 
dar (...) Este es el portogués questava en el Real. Esto fue a la partida de Linares e Su Alteza me lo mandó dar en persona, en que montan: 10.000 maravedís ${ }^{23}$.

El primer Cabildo eclesiástico de Málaga y la intervención en él del Obispo de Ávila

De regreso de Aragón donde habían celebrado Cortes, los Reyes Católicos y su amplia comitiva de la que formaban parte ambos obispos el de Ávila ya veterano y el de Málaga, recién consagrado por Fray Hernando y probablemente en Zaragoza, se detuvieron en Murcia desde el 26 de abril y todo el mes de mayo. En 30 de abril firmaron los Reyes casi una veintena de reales cédulas de presentación ${ }^{24}$ por las cuales, usando de las facultades que les daba el Real Patronato sobre las iglesias del Reino de Granada, presentaban al obispo de Málaga don Pedro de Toledo a una serie de personas hábiles y suficientes para desempeñar los cargos y oficios inherentes a las Prebendas del Cabildo Catedral de Málaga. Todas ellas fueron escritas por el secretario real Alonso de Ávila. Al pie de ellas, lo que indica la intervención de Talavera en la selección de personas a este fin, están rubricadas por la firma autógrafa del obispo de Ávila, «ABULENSIS».

Fray Hernando cooperó al afianzamiento de este cabildo malacitano y a la provisión de clero suficiente y digno para que rigiesen las parroquias y hospitales del nuevo y dilatado obispado, invitando a muchos de los clérigos de su dícesis, a realizar este apostolado misional en una tierra no exenta de peligros ya que era fronteriza de moros por el norte y por el sur. Nos consta de un buen número de clérigos abulenses que se afincaron aquí y alguno de ellos, de gran renombre y categoría como lo fue Don Juan Rodríguez D'Alva (o de Ávila, como reza en otros documentos). Fue presentado por los Patronos ante el Obispo Toledo, el que era Capellán Real Don Juan Rodríguez de Ávila «acatando la sufiçiençia e ydoneydad e por le hazer bien e merçed»' para ocupar la canongía de Tesorero en el Cabildo Catedralicio malacitano, según que la erigió el muy Reverendo en Cristo Cardenal de España. Llegó este hombre al Real sobre Málaga, dentro del séquito del obispo de Ávila al que servía como secretario y mantuvo influencia personal y decisiva en la preparación y organización del culto en la primitiva capilla que, en la catedral-mezquita, como primera parroquia, había de atender a las necesidades espirituales de la primera población cristiana. Oriundo de la diócesis de Ávila, comenzó como capellán y «familian»

\footnotetext{
${ }^{23}$ Ibid., F. $6 \mathrm{r}$.

${ }^{24}$ AGS: Registro General del Sello, abril 1488. Vide etiam: V. GonzÁlez SAnCHEZ, MÁLAGA: Perfiles..., pp. 231 a 246.
} 
de su obispo quien, como hemos dicho, se desprendió de sus muchos y leales servicios, a favor de la Iglesia de Málaga. De entre los muchos apuntes del ya conocido Libro del Limosnero, entresacamos:

\footnotetext{
- "Conpré un libro para bautizar e dar los sacramentos, por mil mrs., sin enquadernar, para Málaga. E quedó en la Iglesia al Capellán Juan Rodrigues quando partimos, para con que diese los Sacramentos" (24 agosto 1487).

- «Conpré unos hierros para fazer ostias para la iglesia de Málaga, por tres florines. Quedaron a Juan Rodríguez (...).)

- «Conpré dos arcas para tener los hornamentos de Málaga, por un castellano, que quedaron a Juan Rodriguez de Alva, capellán.»

- «Que dí a Juan Rodríguez, Capellán del Rey, que le furtaron su barjoleta (=bolsa) e el breviario con quanto tenía, dos florines, que no tenía blanca.s

- «A Juan Rodriguez, el del obispo, 2.000 maravedis.»

- «Di a Salinas, que quedó a pesar la plata que recibió Juan Rodríguez, Capellán de Su alteza, en Málaga, çinco reáles, que juró que no tenía con qué quedar.»

- «Dí a Juar Rodríguez d’Alva (...) que quedó en la Iglesia de Málaga con las capas e ornamentos della çient reales (...) por mandado del Obispo de Avila.»)
}

El Tesorero Juan Rodríguez Dalva, junto con el canónigo portugués Martin Gil, solicitaban licencia en 1496 para roturar cierta parte de monte para tierra de sembradura. Se les concedió por parte del Corregidor y se les adjudicaron 30 aranzadas a cada uno bajo ciertas condiciones. Pero por un asiento posterior, se hace constar que «(...) son fallesçidos y no cunplieron la condiçión.»

Por todo lo expuesto, bien podemos afirmar que la Iglesia de Ávila a través de su obispo y de otros personajes y de otros medios de carácter material, contribuyó de modo eficaz a la puesta en marcha de la Diócesis de Málaga que en cierto modo puede considerarse «hija» de aquella. Muchas de sus prácticas y costumbres se reprodujeron aquí. Más tarde lo haria en favor de las demás Iglesias del Reino de Granada hasta que esta ciudad fue rescatada del Islam. Entonces el obispado de Ávila hizo la donación suprema de uno de sus valores más representativos como era la cesión de su Pastor a favor de la grey granadina.

Es cierto que por todo el celo apostólico que aquí derrochó Fray Hernando de Talavera, recibió repartimiento de tierras y heredades por parte de Sus Altezas, en "alguna remuneraçión de vuestros muchos serviçios» y de igual manera también sus familiares y criados, pero el servicio misional y espiritual que hicieron a la Cristiandad sólo Dios pudo recompensárselo del modo que El solamente puede hacer.

Lope de Talavera era sobrino de Fray Hernando, luchó contra los moros aqứ como escudero de las Guardas y se asentó por vecino de Málaga el 9 de diciembre de 1488 y recibió casas y heredades por vecindad. 
A los demás criados del obispo de Ávila se les señalaron y repartieron 35 fanegadas de tierra de sembradura a cada uno, en la alquería de Jarazmín, por merced de Sus Altezas, medidas por Alonso de la Vega y para repartir entre las personas siguientes: Andrés de Covarrubias, Alonso de Palencia, Juan de León, Juan de Solier, Lope de Talavera y Juan Rodriguez de Ávila quien quedó en Málaga como organista ${ }^{25}$.

El obispo de Málaga murió, como sabemos, confortado con la palabra y la absolución «in articulo mortis» de su «padre y maestro» Fray Hernando, en agosto de 1499. El Arzobispo de Granada, como testamentario, se cuidó de resolver y concluir los problemas que su discípulo le encomendó y por cierto, lo hizo fiel y piadosamente muy pocos meses antes de morir.

Antes, en todo tiempo defendió, amparó y aconsejó al obispo Toledo, como en cierta carta que dirigía a la Reina Católica en la que escribía:

«El obispo de Málaga vino aquí por me dar el palio arzobispal y por comunicar conmigo muchas cosas del regimiento de su iglesia y aun de su casa (...). Dimos orden en todo y partiose enhorabuena libre y consolado de mucha pena que tenfa de le vers ${ }^{26}$.

Con la muerte de uno y otro se cerraron dos capítulos importantes en ambos obispados Málaga y Granada cuyos cimientos de Fe y de vida cristiana, fueron puestos por estos dos varones virtuosos que, afios antes, trabajaron también la tierra fértil de la diócesis que tuvo por primer obispo a San Segundo.

${ }^{25}$ ACCM: Leg. 669, Repartimientos, lib. VI, Fols. 19 y 90.

${ }^{26}$ AGS: Estado. Leg. $1,2^{\circ}$, fol.343. Carta de Fray Hernando de Talavera a la Reina Católica. Autógrafa. S/f. (hacia 1493).

Actas del I Congreso de Historia de la Iglesia y el Mundo Hispánico

Hispania Sacra, 52 (2000) 